\section{PENELITIAN PENGARUH VARIASI JUMLAH \\ PIGMEN TERHADAP KENAMPAKAN RAJAH DAN \\ KUAT REKAT CAT TUTUP KULIT ATASAN SEPATU DARI \\ KULIT SAPI DENGAN TIPE FINISH SEMI ANILIN}

Oleh : Emiliana K, Widhiati, Emi Sulistyo astuti, R.Jaka Susila

\section{ABSTRACT}

The purpose of this research is to know the influence of sum of pigmen to concern the ap pearance of the grain and the adhesion of finish of the upper leather for cattle hide. Materi als used in this study were 6 sides second quality wet blue leather catle hide, the treatment of which is variation of pigmen $(20 \mathrm{gram}, 40 \mathrm{gram}$ and $60 \mathrm{gram}$ in $1000 \mathrm{gram}$ solution). The data which were statistically analyzed using Completely Randomized Design (CRD) and Least Significant Difference (LSD) show that the appearance of the appearance of the grain tets is significant and the best result for using 20 gram pigment with score 69.93. Then for the adhesion of finish test (wet and dry) indicated that is not significant between three varia. tion of sum of pigent (20gram, $40 \mathrm{gram}, 60 \mathrm{gram}$ ). Adhesion of finish (wet and drv) included high quality for the grade of shoe upeer with the score is $200 \mathrm{gr} / \mathrm{cm}$ (wet, minimum grade 3 ) and the score is $543.75 \mathrm{gr} / \mathrm{cm}$ (dry minimum grade 1 ).

\section{INTISARI}

Tujuan dari penelitian ini adalah untuk mengetahui pengaruh jumlah pigment terhadap kenampakan rajah dan kuat rekat cat tutup kulit atasan sepatu dari kulit sapi. Bahan yang digunakan dalam penelitian ini adelah 6 kulit belahan sapi krom basah (wet blue) kualitas nomor 2 yang disamak menjadi kulit atasan sepatu dengan menggunakan 3 (tiga) variasi penggunaan jumlah pigment masing-masing 20 gram, 40 gram, dan 60 gram dalam 1000 gram larutan. Hasil analisa statistik dengan metoda CRD (Completely Randomized Design) dan Uji Beda Nyata Terkecil (LSD) menunjukkan bahwa ada perbedaan nyata pada uji kenampakan rajah, dan hasil yang terbaik untuk penggunaan 20 gram pigment. Sedangkan untuk uji kuat rekat cat tutup (basah dan kering) menunjukkan bahwa ada beda nyata antara tiga variasi jumlah pigment ( $20 \mathrm{gram}, 40 \mathrm{gram}, 60 \mathrm{gram}$ ). Kuat rekat cat tutup (basah dan kering) termasuk kualitas tinggi untuk tingkatan atasan sepatu, dengan nilai $200 \mathrm{gr} / \mathrm{cm}$ (basah, minimum tingkatan 2) dan nilai $543,75 \mathrm{gr} / \mathrm{cm}$ (kering, minimum tingkatan l)

\section{PENDAHULUAN}

Kulit untuk atasan sepatu dapat dibuat dari bermacam-macam jenis kulit seperti kulit kambyng kulit reptil, kulit sapi dan lain-lain. Kulit boks adalah kulit jadi yang berasal acia kulit sapi atau anak sapi yang disamak krom dan umumnya digunakan untuk kulit atasan sepatu(2). Tipe finish untuk kulit atasan sepatu dapat berupa finish anilin, semi anilin, glazed dan lain-lain. Untuk mendapatkan pewarnaan terang biasanya dengan menggunakan finish anilin dimana dalam komposisi cairan cat tutup harus tepat dan homogen agar rajah kulit masih tampak alami karen pigment yang digunakan bersifat transparan. Agar diperoleh hasil yang baik, kul yang digunakan harus kualitas nomor 1 (tidak ada cacat pada rajah), padahal untu mendapatkan kualitas nomor 1 sangat sulit karena prosentase kulit sapi yang tida ada cacatnya sangat rendah sehingga produksi kulit anilin asli hampir tidak dilakukat ecara tetap. Tetapi akhir-akhir ini teknik finishing yang baru telah dikembanok exdasarkan pada penggunaan kombinasi anilin dyestuffs dan pignent ban iki panchent dan ak: menghasilkan pengaruh finish yang mirip dengan anilin asli (1)

Kulit full grain dengan permukaan kulit yang mempunyai sedikit cacal par ajah kurang cocok untuk diproses dengan finish anilin dan lebih cocok dipros dengan finish semi anilin. Pengecatan tutup dengan tipe finish semi anilin dap memberikan pengaruh menyamarkan atau menutup cacat-cacat pada rajah, sehimg: kulityang digunakan dapat berasal dari kulit kualitas nomor 2 dan dengan demiki: kulit kuaditas nomor 2 dapat ditingkatkan mutunya. Yang dimaksud dengan fim semi anilin adalah tipe finish dengan pigment transparant untuk menyamarkan at menutup cacat-cacat pada rajah atau permukaan yang tidak rata pada pengecat dasar. Pada dasarnya finish semi anilin adalah merupakan lapisan tipis ya mengandung sejumlah kecil pigment anilin organik atau an organik agar cac: catat pada rajah tersamar atau tertutup. Jumlah pigment yang digunakan harus sedi saja sehingga pola kantong rambut masih tampak dan dapat dikatakan lapisann harus masih transparan dan sifat-sifat alami kulit atau kenampakan rajah ma: tampak. Menurut pustaka (5), pigment yang digunakan dalam finish semi ani sebanyak 50 bagian pigment organik dan 50 pigment anilin, sedangkan menurut digunakan 20 bagian pigment yang berfungsi untuk menutupi cacat rajah d meratakan permukaan serta memberikan warna pada kulit. Koteswara mengatakan bahwa makin banyak pigment maka daya menutup semakin tinggi c menurut (6) pengurangan jumlah pigment akan mengurangi daya menutup tet menaikkan kecerahan (brilliance) dan ketahanan gosok (rub fastness).

Untuk mendapatkan pengaruh finish yang spesifik, yang penting bukan hat pada komposisi cat tutup tetapi juga pada metode penerapan finishing (applicat of finish). Metode penerapan finishing dapat dilakukan dengan tangan, seperti si (brush coating), pad (padroating) dan semprot dengan tangan. Disamping itu da menggunakan mesin seperti roller coating, mesin semprot (automatic conve belt spraying) dan curtain coating $(3,5,6,7)$. Daya rekat dan daya menutup cat tu akan baik bila menggunakan mesin (5), daya rekat cat tutup juga tergantung $p$ kondisi kulit, tipe bahan penyamak, macam minyak, jumlah lapisan dan bahan fin ing yang digunakan $(7,8)$. Sedangkan Soysa mengatakan bahwa tingkatan d rekat dari cat tutup (grade adhesion of finish) adalah sebagai berikut :

* Tingkatan (grade) 1 nilai 350 lebih

* Tingkatan (grade) 2 nilai $250-349$

* Tingkatan (grade) 3 nilai $200-249$
Majalah Barang Kulit, Karet dan Pla 
* Tingkatan (grade) 4 nilai $150-199$

* Tingkatan (grade) 5 nilai $100-149$

Sedangkan kualitas bahan yang digunakan untuk sepatu :

\begin{tabular}{|c|c|c|}
\hline Tingkat Kualitas & Uji Kering (gr/cm) & Uji Basah (gr/cm) \\
\hline $\begin{array}{c}\text { Kualitas linggi } \\
\text { Kualitas sedang }\end{array}$ & $\begin{array}{l}\text { grade } 2 \text { atau diatasnya } \\
\text { grade } 3 \text { atau diatasnya }\end{array}$ & $\begin{array}{c}\text { grade } 3 \text { atau diatasnya } \\
\text { grade } 4 \text { atau diatasnya }\end{array}$ \\
\hline
\end{tabular}

\section{MATERI DAN METODA}

\section{A. Materi}

Materi dalam penelitian ini berupa

1. Bahan

$$
\text { a. Kulit }
$$

Kulit yang digunakan sebanyak 6 belahan kulit sapi krom basah (wet blue) kualitas nomor 2.

b. Khemikalia

Khemikalia untuk proses dari kulit krom basah (wet blue) sampai dengat kulit kras warna adalah chromosal B, Mimosa, Actan RS, Taningan OS, cat dasar. Invasol, Provol BA dan bahan-bahan pembantu untuk penyamakan. Sedangkan khemikalia untuk finishing adalah pigment (pewarna), bahan pembentuk lapisan (film), bahan pełunak (wax), bahan penetrasi (penetrator), emulsi lak.

\section{Alat/mesin}

a. Alat untuk proses dan finishing kulit :

Drum penyamakan, timbangan, mangkok, pengaduk, saringan, alat semprot, alat pentang, alat peregang dan mesin setrika

b. Alat untuk pengujian.:

Alat uji untuk kuat rekat cat tutup (adhesion of finish tester).

\section{B. Metoda}

1. Pelaksanaan proses penyamakan ulang sampai dengan pewarnaan dasar.

Külit sapi krom basah sebanyak 6 belahan diproses menjadi kulit boks dengan menggunakan bahan penyamak kombinasi krom (4\%), sintetis $(4 \%)$, dan nabati $(2 \%)$. Metode proses sesuai dengan prosedur proses penyamakan kulit dari Balai Penelitian Barang Kulit BBKKP.

\section{Pelaksanaan proses pengecatan tutup (finishing)}

Kulit yang telah mengalami peregangan(staking), pementangan dan dirapikan kemudian dilakukan pengecatan tutup dengan komposisi sebagai berikut
Komposisi lapisan pigment

$$
\begin{array}{lcl}
\text { * Pigment } & (20,40,60) & \text { gram } \\
\text { * RU 3989 } & 50 & \text { gram } \\
\text { * RA 2357 } & 150 & \text { gram } \\
\text { * Fi 50 } & 25 & \text { gram } \\
\text { * Wax Top B } & 20 & \text { gram } \\
\text { * Penetrator } & 15 & \text { gram } \\
\text { * Air } & (720,700,680) \text { gram semprot 3 kali }
\end{array}
$$

Komposisi lapisan atas (top coat)

$$
\begin{array}{lrl}
\text { * IS } 5575 & 250 & \text { gram } \\
\text { * Thinner } & 750 & \text { gram } \\
\text { * LD } & 12 & \text { gram, semprot I kali }
\end{array}
$$

Setrika dengan suhu $80 \mathrm{C}$, tekanan $100 \mathrm{Bar}$, waktu 1 detik

\section{Pengujian}

Kulit atasan sepatu hasil penelitian diuji

a. Fisis

Kulit rekat cat tutup baik secara basah maupun secara kering

b. Organoleptis

Kenampakan rajah (appearance of grain) dengan batasan ini sebagai berik

Baik : $70-79$

Cukup : $60-69$

Kurang : $50-59$

\section{HASIL DAN PEMBAHASAN}

A. Hasil

1. Hasil uji kenampakan rajah

Kenampakan rajah kulit atasan sepatu dinilai secara organoleptis oleh 14 pane dengan hasil sebâgai berikut :

Tabel 1.

Hasil uji kenampakan rajah

\begin{tabular}{c|c|c|c}
\hline Panelis & A (20 gr $)$ & B (40 gr $)$ & C (60 gr) \\
\hline 1. & 70 & 70 & 70 \\
2. & 70 & 70 & 70 \\
3. & 70 & 70 & 67 \\
4. & 70 & 69 & 70 \\
5. & 76 & 74 & 62 \\
6. & 76 & 77 & 64 \\
7. & 69 & 68 & 62 \\
8. & 68 & 68 & 62
\end{tabular}

Majalah Barang Kulit, Karet dan Pl: 


\begin{tabular}{|c|c|c|c|}
\hline $\begin{array}{l}9 . \\
10 \\
11 . \\
12 \\
13 \\
14 .\end{array}$ & $\begin{array}{l}67 \\
70 \\
75 \\
6.5 \\
65 \\
68\end{array}$ & $\begin{array}{l}68 \\
68 \\
65 \\
68 \\
61 \\
65\end{array}$ & $\begin{array}{l}69 \\
64 \\
60 \\
60 \\
61 \\
64\end{array}$ \\
\hline \multicolumn{2}{|c|}{ Rata-rata: } & 68,64 & 64,71 \\
\hline
\end{tabular}

Taluel 2

Analisa Varian uji kenampakan rajahı

\begin{tabular}{|l|c|c|c|c|}
\hline \multicolumn{1}{|c|}{ Sumber } & d.f & SS & MS & Probabilitas \\
\hline Variasi & 2 & 206,62 & 103,31 & 0,00189 \\
Perlakuan & 2 & 545,00 & 13,97 & \\
Error & 39 & 751,69 & & \\
\hline Jumlah & 41 & & \\
\hline
\end{tabular}

Ada perbedaan nyata diantara variasi $A, B$ dan $C(P \leq 0,05)$

Tabel 3

Analisa LSD

\begin{tabular}{|c|c|c|c|}
\hline Perlakuan & Total & Rata-rata & Notasi LSD 5\% \\
\hline C & 906 & 64,714 & a \\
B & 961 & 68,640 & b \\
A & 979 & 69,929 & c \\
\hline
\end{tabular}

Variasi A mempunyai kenampakan rajah yang lebih baik dibanding variasi $B$ dan $C$

\section{Hasil uji rekat cat tutup}

a. Kuat rekat cat tutup secara basah

Tabel 4

Hasil uji kuat rekat cat tutup secara basah

\begin{tabular}{|c|c|c|c|}
\hline Ulangan & A (20gram) & B (40gram) & C (60gram) \\
\hline 1 & 257,17 & 183,33 & 183,33 \\
2 & 145,83 & 179,17 & 183,33 \\
\hline Jumlah: & 400,00 & 362,50 & 366,66 \\
Rata-rata : & 200,00 & 181,50 & 183,33 \\
\hline
\end{tabular}

Tabel 5

Analisa Varian uji kuat rekat cat tutup secara basah

\begin{tabular}{|l|c|c|c|c|}
\hline Sumber & d.f & SS & MS & F hitung \\
\hline Variasi & & & & \\
Perlakuan & 2 & 422,52 & 211,26 & 9,55 \\
Error & 3 & 145,83 & 1959,14 & \\
Jumlah & 5 & 568,35 & & \\
\hline
\end{tabular}

$\mathrm{F}$ hitung $\leq \mathrm{F}$ tabel, tidak ada perbedaan kuat rekat cat tutup secara basah dianta variasi $\mathrm{A}, \mathrm{B}$ dan $\mathrm{C}$.

b. Kuat rekat cat tutup secara kering

Tabel 6

Hasil uji kuat rekat cat tutup secara kering

\begin{tabular}{|c|c|c|c|}
\hline Ulangan & A (20gram) & B (40gram) & C (60gram) \\
\hline 1 & 587,50 & 333,33 & 383,33 \\
2 & 500,00 & 670,83 & 500,00 \\
Jumlah & 1087,50 & 1004,16 & 1166,67 \\
Rata-rata & 543,75 & 502,08 & 583,33 \\
\hline
\end{tabular}

Tabel 7

Analisa varian uji kuat rekat cat tutup secara kering 


\begin{tabular}{|l|c|c|c|c|}
\hline Sumber Variasi & d.f & SS & MS & F hitung \\
\hline Perlakuan & 2 & $10.558,47$ & $5.269,2.3$ & $0,23.38$ \\
Irror & 3 & $67.587,19$ & $22529,(66$, & \\
\hline Jumlah & 5 & $78.145,66$ & & \\
\hline
\end{tabular}

F hitung $\leq$ F tabel, tidak ada perbedaan yang nyata kuat rekat cat (utup) secara kering diantara variasi $A, B$, dan $C$.

\section{Pembahasan}

\section{Kenampakan rajah}

Hasil analis avarian menunjukkan bahwa perlakuan pengecalan tutup dengan variasi jumlah pigment ternyata mempengaruhi kenampakan rajah kulit $(\mathrm{P} \leq 0,05)$ dan dari analisa Beda Nyata Terkecil (ISD) menunjukkan bahwa penggunaan jumlah pigment 20 gram atau yang paling sedikit jumlahnya dibanding penggunaan pigment 40 gram dan 60 gram, ternyata dihasilkan kenampakan rajah yang lebih baik (Natu ral). Hal ini sesuai dengan pendapat Tuch DH bahwa pemakaian pigment yang berlebihan dapat menyimpang dari sifat-sifat alami kulit dan akan terlibat seperti plastik dan menurutnya untuk finish semi anilin, penggunaaan pigment harus sedikit saja supaya pola kantung rambut masih tampak. Hal ini sesuai pula dengan pendapat Koteswara bahwa semakin banyak pigment maka daya menutupnya semakin tinggi dan juga menurut Thortensen pengurangan jumlah pigment akan mengurangi daya menutup tetapi menaikkan kererahan (brilliance) sehingga karena lapisan cat tutup yang diberikan agak transparant ( 20 gram pigment) maka rajah asli dari kulit masih tampak.

\section{Kuat rekat cat tutup}

Hasil analisa varian menunjukkan bahwa perlakuan pengecatan tutup dengan variasi jumlah pigment tidak mempengaruhi kuat rekat cat tutup baik secarabasah maupun secara kering. Untuk kuat rekat cat tutup secara basah mempunyai nilai $200 \mathrm{gr} / \mathrm{cm}$ (grade 3), sehingga dikategorikan sebagai kualitas tinggi untuk bahan atasan sepatu, yang menurut penelitian Soysa minimumgrade 3 pada uji kuat rekat secara basah. Sedangkan untuk kuat rekat cat tutup secara kering mempunyai nilai diatas $350 \mathrm{gr}$ $\mathrm{cm}$ yang dalam hal ini termasuk kategori kualitas tinggi pula untuk bahan atasan sepatu, yang menurut Soysa minimum grade 2 atau yang lcbih baik. Hal ini mungkin disebabkan karena kondisi kulit yang digunakan baik, minyak yang digunakan dalam proses tidak berlebihan dan bahan-bahan cat tutup yang dipakai dapat merekat dengan baik pada permukatan kulit dan antara lapisan pigment dengan lapisan atas lak dapat berkatitan dengan baik.
Hal im sesuai dengan pendapat Tuck DH dan Thortensen bahwa daya rekat ca tergantung pada kondisi kulit, tipe bahan penyamak, macam minyak yang digunakan jumlah lapisan dan bahan finishing yang digunakan.

\section{KESIMPULAN}

Dari hasil penelitian dan pembahasan dapat ditarik kesimpulan

1. Kenampakan rajah dipengaruhi oleh jumlah pigment yang digunakat Semakin sedikit penggunaan pigment maka rajah kulit yang alami masih tampa terlihat. Dalam penelitian ini kenampakan rajah yang paling baik (alami) dicap: oleh penggunaan pigment 20 gram (paling sedikit), dengan nilai 69,93.

2. Kuat rekat cat tutup tidak dipengaruhi oleh jumlah pigment yang digunakar Dalam penelitian ini, hasil kuat rekat cat tutup baik secara basah maupun secas kering menunjukkan hasil yang baik dalam kategori kualitas tinggi untuk atasa sepatu. Kuat rekat cat tutup secara basah mempunyai nilai $200 \mathrm{gr} / \mathrm{cm}$ (grade 3 ) da kuat rekat cat tutup secar a kering mempunyai nilai diatas $350 \mathrm{gr} / \mathrm{cm}$ (grade 1).

\section{DAFTAR PUSTAKA}

1. BASH, Leather Dyer's Manual Badische Anilin and Soda Fabric AG, Ludwigs! fenam Rhein

2. Departemen Perindustrian, 1989, SNI.06 - 0234 - 1989, Mutu dan cara uji kul Boks

3. Indofil Chemical Limited, L eather Finishing Manual , 34 Circus Avenue, Calcu 700017

4 Koteswara dkk, 1979, Dyeing and Finishing of I eather, Central Leather Rese ch and Institute, Adyar Madras

5. Tuch DH, 1981, The Manufacture of Upper Leather, Tropical Product Institu lingland

6. Thortensen T, 1985, Practical Leather Technology. Robert E. Krieger Publisi ( ompany, Malabar Florida

7. Sharphouse JH, 1971, Leather Technician's Hand Book Leather, Produser's A ociation, 9 st Thomas street, London

8. Soysa, WMA, 1982, Report and Physical Test Fiuipment, Proyek Balai Penger bangan dan Penelitian Kulit ININDO

Majalah Barang Kulit, Karet dan Plas 